\title{
Infundibular Stenosis
}

National Cancer Institute

\section{Source}

National Cancer Institute. Infundibular Stenosis. NCI Thesaurus. Code C123250.

Narrowing of the infundibulum to the calyx, which produces an impediment to urine flow. 